\title{
METODOLOGIAS PARA O ENSINO DE ASTRONO- MIA E FÍSICA ATRAVÉS DA CONSTRUÇÃO DE TELESCÓPIOS ${ }^{+*}$
}

Tamara de O. Bernardes

Departamento de Física - Unesp

Gustavo Iachel

Rosa M. F. Scalvi

Departamento de Física - Unesp

Programa de Pós Graduação em Educação para Ciência

Faculdade de Ciências - Unesp

Bauru - SP

\section{Resumo}

Este trabalho propõe a construção manual de telescópios refletores como ferramenta didática para o ensino de Física e Astronomia. Cada etapa da construção pode ser aliada a conteúdos de óptica geométrica e óptica Física com abordagens diferentes dependendo do nível de ensino com que se trabalha, podendo ser Fundamental, Médio ou de Graduação. Foi possível verificar que a construção de telescópios refletores do tipo newtoniano mostrou ser acessivel e facilmente compreendida pelos estudantes de graduação envolvidos no projeto, tornando o aprendizado de Física e outras ciências correlatas motivador e eficiente. Já a construção do telescópio refletor do tipo cassegrain deve ser abordada apenas envolvendo alunos de cursos superiores, pois envolve processos mais complexos na obtenção e análise das superficies dos espelhos primário e secundário. Além disso, com o desenvolvimento da construção dos aparelhos, teve origem a criação do Grupo de Estudos de Astronomia no Departamento de Física da Unesp,

\footnotetext{
${ }^{+}$Methodology for Astronomy and Physics teaching through telescope construction

* Recebido: janeiro de 2007. Aceito: dezembro de2007.
} 
campus de Bauru, onde temas relacionados ao ensino de Astronomia têm sido abordados e discutidos junto a alunos e professores do Ensino Fundamental e Médio. Concluímos que a utilização dos telescópios junto aos alunos do Ensino Médio e Fundamental tem sido um grande incentivo à contemplação do céu e à compreensão de muitos fenômenos celestes, relacionando-os com conteúdos de Física e também outras ciências, como Matemática, Geografia, Educação Ambiental e Meteorologia.

Palavras-chave: Astronomia; telescópios; Ensino de Física; ferramentas didáticas.

\begin{abstract}
This work contemplates the construction of reflecting telescopes as didactic tool for Physics and Astronomy teaching. Each stage of the construction can be linked with the contents of geometric optics and optical physics with different approaches, depending on the education level of working: Fundamental, High-School or Graduation. It was possible to verify that the construction of reflecting telescopes of the Newtonian type shows up as accessible and easily understood by graduated students involved in the project, turning the learning of Physics and other related sciences as motivating and efficient. In the other hand, the construction of the reflecting telescope of Cassegrain type must be considered only when involving students of graduation level, because it concerns more complex processes in the accomplishment and analysis of the primary and secondary mirror surfaces. Moreover, the development of the apparatus construction yields the creation of the Group of Studies of Astronomy in the Department of Physics of the Unesp, campus of Bauru, where subjects related to astronomy education have been treated and discussed jointly with students and teachers of Fundamental and High School levels. Our conclusion is that the use of the telescopes to teach students of Fundamental and High School levels has been a great incentive to the observation of the sky and to the comprehension of many celestial phenomena, relating them to contents of Physics and also
\end{abstract}




\begin{abstract}
other sciences, such as Mathematics, Geography, Environmental education and Meteorology.
\end{abstract}

Keywords: Astronomy; telescopes; Physics Teaching; didactic tools.

\title{
I. Introdução
}

O ensino de Astronomia pode ser iniciado pela observação do céu a vista desarmada, começando com o reconhecimento deste e, posteriormente, utilizando instrumentos astronômicos ${ }^{1}$, como binóculos, telescópio refrator (luneta) e o telescópio refletor. Contudo, nota-se que aprender nem sempre é uma tarefa atraente para os alunos, e um dos fatores para que isso aconteça é quando o aprendizado envolve somente bases teóricas dificultando ao aluno as relações com o mundo ao redor. Assim, utilizar-se da construção de telescópios refratores e refletores como ferramenta no ensino de Astronomia pode ser tarefa bastante motivadora, uma vez que, desta maneira, os alunos conseguem entender melhor como funcionam os aparelhos e o que se pode fazer com estes, e relacionar isso com as observações, logo com o estudo da Astronomia, e também com o ensino de Física, uma vez que são todas áreas correlatas. Além disso, quando o aluno percebe a importância do estudo da Astronomia, mesmo aquela realizada de forma simples e por astrônomos amadores, ele aprende a contemplar o céu de maneira sistemática e a preocupar-se com o entendimento de muitos fenômenos celestes, compreendendo que esta talvez seja a única ciência em que amadores contribuem significativamente com dados e informações para a comunidade científica profissional ${ }^{2}$.

Dessa forma, pode se afirmar que a Astronomia é uma das áreas que mais atrai a atenção e desperta a curiosidade dos alunos, desde os primeiros anos escolares até sua formação nos cursos de graduação, abrangendo todas as áreas, como Matemática, Geografia, Pedagogia e, principalmente, a Física. O ensino de Astronomia nas escolas de Ensino Fundamental e Médio tem sido objeto de diversas pesquisas na área de Educação em $\mathrm{Ciência}^{3}$, mostrando que no seu ensino encontram-se diversos problemas que necessitam ser estudados visando, principalmente, a melhoria da qualidade dos docentes que o ministram ${ }^{4}$. Diante dessa realidade, este trabalho pretende proporcionar aos alunos dos diversos cursos de Licenciatura, futuros professores de Ensino Médio, conhecimento prático e teórico na área de observações astronômicas através da construção e utilização de telescópios refletores, do tipo newtoniano e cassegrain, e também de telescópios refratores (lunetas), 
cuja construção é menos complexa. Outro objetivo fundamental deste trabalho é motivar os alunos de Licenciatura em Física a refletir e discutir acerca dos fenômenos físicos relacionados principalmente à óptica, através do estudo de Astronomia, colaborando assim no atendimento de pesquisas que retratam a deficiência no ensino nessa área. Além disso, através do trabalho desenvolvido pelo Grupo de Estudos de Astronomia do Departamento de Física da Unesp - Bauru, temas como Astronomia de Posição, Estrelas e Galáxias, Fases da Lua, Evolução dos Telescópios e muitos outros, são estudados e preparados para serem discutidos junto aos alunos de Ensino Médio e Fundamental.

\section{Materiais e métodos}

A primeira parte deste trabalho envolve a construção de um telescópio newtoniano através de método totalmente artesanal, por alunos do curso de Licenciatura em Física. A construção de um telescópio envolve conceitos tanto de Física quanto de Astronomia, e estes conceitos podem ser explorados em níveis específicos, dependendo a quem são destinados. Por exemplo, para que se entenda cada uma das características do aparelho que irá ser construído, é necessário que se tenha um conhecimento básico em Astronomia ${ }^{5}$ abrangendo, por exemplo, a Astronomia de posição; classificação dos corpos celestes (estrelas, galáxias, planetas, nebulosas, etc.); identificação dos corpos celestes com seus respectivos movimentos em relação à Terra; magnitude (do corpo celeste), luminosidade, etc. Estes são de suma importância para observação, pois, conhecidas as características do instrumento, é possível saber o que se consegue observar com este. Um exemplo é um aparelho que capta pouca luminosidade, sendo mais adequado para observar objetos mais luminosos como as estrelas, ou o inverso que serviria para observar planetas. Dessa maneira, para fazer esta análise, é necessário conhecimento prévio de conceitos como: i) óptica do instrumento, ou seja, entender "como funciona o telescópio", pois isso envolve conceitos de óptica, tais como reflexão, refração e difração, uma vez que a luz, até chegar ao observador, passa por uma reflexão no espelho primário, e outra no espelho secundário; ii) qualidade óptica do aparelho que irá definir cada um dos componentes ópticos, sendo que o espelho primário é o que tem maior influência para que se tenha um bom instrumento e iii) características básicas do instrumento, como campo, aumento, luminosidade, magnitude e poder separador, que permitirá o que irá se observar. A análise de alguns dos problemas que podem ocorrer com o espelho principal e como a observação será influenciada por isto pode ser resumida na tabela 1 . 
Tabela 1- Alguns defeitos do espelho principal e conseqüências na observação.

\begin{tabular}{l|l}
\hline \multicolumn{1}{c|}{ Defeitos } \\
$\begin{array}{l}\text { Espelho não parabólico (vários } \\
\text { focos) }\end{array}$ & \begin{tabular}{l}
\multicolumn{1}{c}{ Influência na observação } \\
Imagem com pouca nitidez
\end{tabular} \\
$\begin{array}{l}\text { Espelho com falta de polimento } \\
\text { (levemente fosco) }\end{array}$ & $\begin{array}{l}\text { Imagem menos luminosa do que o aparelho } \\
\text { poderia captar }\end{array}$ \\
Espelho com astigmatismo & \begin{tabular}{l} 
Imagem alongada e distorcida \\
\hline
\end{tabular}
\end{tabular}

A construção artesanal do telescópio newtoniano utilizado neste trabalho pode ser resumidamente descrita da seguinte forma ${ }^{6}$ :

1) corte dos vidros no formato circular, com diâmetro aproximado de $20 \mathrm{~cm}$, sendo que um dos vidros possui espessura de $10 \mathrm{~mm}$ e outro vidro possui espessura de $20 \mathrm{~mm}$. O bloco de vidro mais espesso dará origem ao espelho primário do telescópio e o bloco menos espesso é utilizado como ferramenta no trabalho de construção; carburundum;

2) esmerilhamento dos vidros utilizando abrasivo adequado, nesse caso

3) polimento do vidro mais espesso, realizado após obter a curvatura do vidro pelo processo anterior;

4) correção da parabolização do vidro utilizando método de Focault ${ }^{7}$;

5) deposição da camada refletora sobre os vidros, obtendo o espelho primário do aparelho;

6) confecção da lente ocular;

7) confecção do espelho secundário, que deve ser plano;

8) alinhamento óptico do aparelho, montado em um tubo $p v c$;

9) confecção dos tripés.

Durante o processo de construção do aparelho, fenômenos como a reflexão de raios paraxiais provenientes de objetos muito distantes, são abordados já na fase de esmerilhamento do espelho primário, uma vez que o vidro, inicialmente plano, deve ser trabalhado até que sua superfície se torne esférica. Essa etapa envolve, por exemplo, medidas sistemáticas da curvatura desse espelho que definirá sua distância focal. Além disso, como os raios provenientes de uma fonte distante são paraxiais, quando incidem em um espelho esférico de médio porte causam aberração esférica e, por isso, a parabolização deve ser realizada para que a superfície do espelho tenha uma forma capaz de refletir todos os raios que incidem qua- 
se paralelos a esta, em um único ponto, que é o foco ${ }^{8}$. Essa análise é acompanhada com a utilização do método de Focault ${ }^{6,7,8}$, que possibilita a visualização real da superfície do vidro, conforme ilustrado na Fig. 1. Nessa fase do processo, o construtor do telescópio tem a oportunidade de verificar, na prática, os efeitos dos fenômenos de interferência e difração da luz, analisando a superfície do vidro, que a olho nu parece ser totalmente plana.
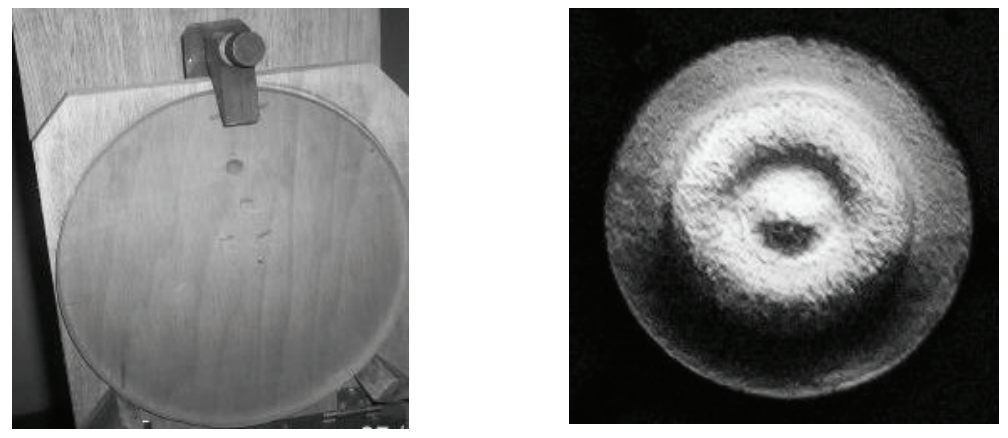

Fig. 1 - Superficie do vidro esmerilhado observada a olho nu e superficie do vidro esmerilhado observada no dispositivo de Focault ${ }^{6}$.

Após o término dos processos de esmerilhamento, polimento e correção da parabolização, o espelho passa pela aluminização e está pronto, tornando-se o espelho principal do aparelho construído.

O espelho secundário também interfere na observação caso não esteja plano, pois se a superfície do espelho apresentar rugosidade da ordem do comprimento de luz que incide no espelho, os raios luz que chegarão ao observador estarão defasados, pois percorrem caminhos diferentes, alterando a imagem e causando aberrações na imagem obtida. Na confecção do espelho secundário, a análise é feita através da observação de franjas de interferência ${ }^{9}$, as quais devem ser completamente paralelas, garantindo a planicidade desse espelho.

As lentes oculares podem apresentar várias aberrações, e ao utilizar apenas uma lente na ocular no telescópio refletor obtido, esta possuirá uma aberração cromática que poderá ser corrigida com outras lentes que minimizem o defeito. Por isso, em geral, as oculares são sistemas de lentes em que cada uma tem uma função específica, por exemplo, uma que corrija aberração cromática, outra que corrija aberração esférica e uma terceira que aumente o campo de visão. A Fig. 2 ilustra a maneira como foi obtida a lente ocular, utilizando material de baixo custo e permi- 
tindo abordar a formação de imagens através da combinação de lentes em dispositivos ópticos.

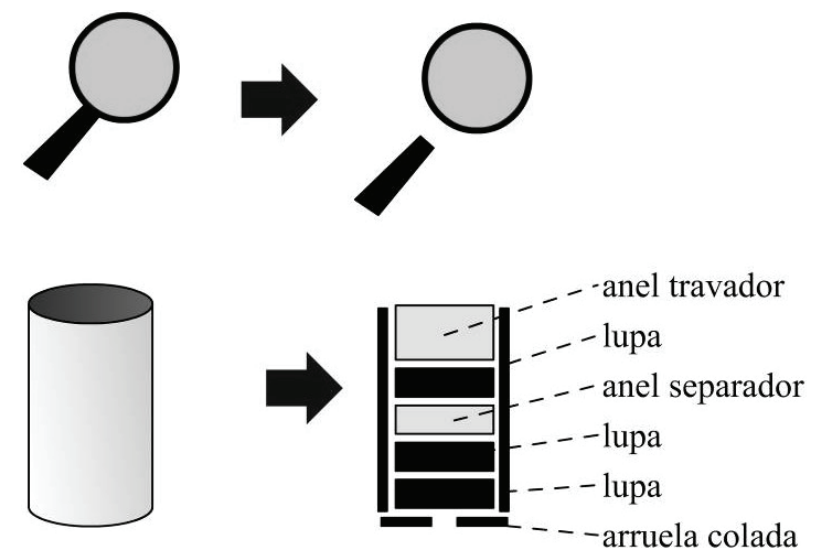

Fig. 2 - Esquema utilizado na obtenção da lente ocular

Conforme mostrado na Fig. 2, a lente ocular foi construída a partir de três lupas de $50 \mathrm{~mm}$ de diâmetro cada, inseridas em um cano de $p v c$ de mesmo diâmetro interno. Para sustentar as lentes, são utilizadas arruelas e dois anéis feitos com tubo pvc. O observador utiliza o orifício da arruela para direcionar seu olho. Nessa etapa da construção, o aluno construtor pode entender dispositivos ópticos que utilizam combinação de lentes, como no caso da ocular construída.

A $2^{\mathrm{a}}$ etapa do trabalho envolve as atividades do Grupo de Estudos de Astronomia, formado por alunos de graduação de Licenciatura em Física e de outros cursos, além de professores do Departamento de Física da Unesp, Bauru. Alguns temas como História da Astronomia e seu ensino no Brasil, Astronomia de Posição, Instrumentos Astronômicos, Sistema Solar, Estrelas e Galáxias, Modelos Astronômicos, Fases da Lua, Buracos Negros, Unidades Astronômicas e Descoberta de Planetas são abordados e discutidos pelo grupo. O conteúdo apresentado por um componente do grupo responsável pelo tema é disponibilizado na forma de apresentações multimídias e, após discussões, sugestões e correções, é utilizado junto aos professores e alunos de Ensino Médio e Fundamental, através de palestras, oficinas e mini-cursos. Além disso, o Grupo de Estudos também se dedica à criação de animações multimídias que irão auxiliar no processo de aprendizagem de Astronomia. 


\section{Resultados e discussões}

A Fig. 3 mostra o telescópio newtoniano construído ${ }^{6}$ através do método brevemente descrito acima, dando origem a um aparelho de ótima qualidade e de baixo custo, em torno de $\mathrm{R} \$ 250,00$ (para o aparelho completo). Além do newtoniano, também foi construído um telescópio do tipo Cassegrain Dall-Kirkham ${ }^{7}$, cuja construção é mais complexa e, por isso, não deve ser muito indicada para se trabalhar com alunos do Ensino Médio. Por outro lado, a observação do céu utilizando dois instrumentos com características diferentes, permite que o aluno de Licenciatura explore mais adequadamente a óptica envolvida na construção dos aparelhos, abordando, por exemplo, a utilização de espelhos planos no newtoniano e de espelhos convexos no cassegrain. Além disso, questões como: "Por que o telescópio cassegrain é menor? Qual a vantagem em utilizar um ou outro? Como se obtém o espelho secundário no cassegrain?”, surgem a cada sessão de observação utilizando os aparelhos construídos pelos alunos do Ensino Médio e que podem ser facilmente respondidas pelos alunos de Licenciatura, responsáveis pela construção dos aparelhos. Nesse caso, as explicações são realizadas através de desenhos esquemáticos na lousa, explicitando a formação da imagem em ambos os aparelhos, ilustrando na prática o conteúdo de óptica geométrica abordado teoricamente em sala de aula do Ensino Médio.
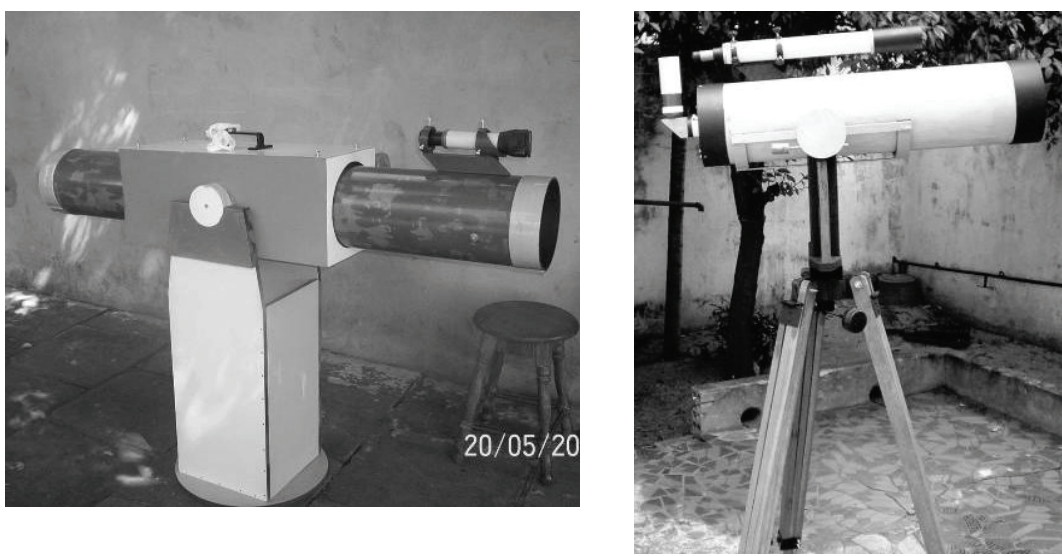

Fig. 3 - Telescópio newtoniano $(f / D=7,1)$ e Telescópio Cassegrain $(f / D=4)$.

O telescópio newtoniano possui relação $F / D=7,1$, onde $f$ é a distância focal e $D$ é o diâmetro do espelho primário $(19 \mathrm{~cm})$. Suas características permitem 
abordar as fotografias lunar, com suas crateras e vales, e planetária, com excelente resolução, observando, por exemplo, as luas de Júpiter, os anéis de Saturno, além de sistemas binários, nebulosas, aglomerados, etc.

O esquema óptico do telescópio Cassegrain apto à observação celeste possui esquema óptico diferente do newtoniano, conforme apresentado na Fig. 4.

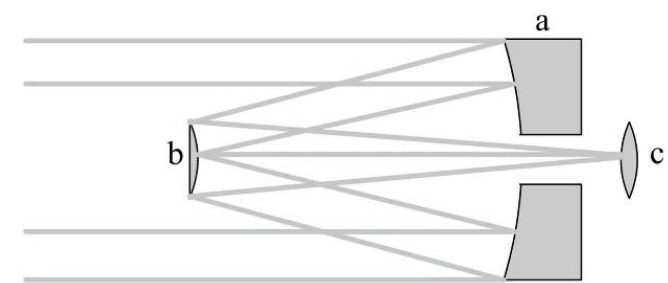

a - Espelho Primário b - Espelho Secundário c-Ocular

Fig. 4 - Esquema óptico de um telescópio cassegrain.

Na Fig. 4, a luz proveniente de um objeto celeste atinge o espelho primário (côncavo e parabólico), reflete para o espelho secundário (convexo e parabólico) onde reflete novamente até chegar à ocular, onde o observador deve estar posicionado. Devido ao espelho secundário ser convexo e parabólico e o espelho primário possuir um furo circular em seu centro, o telescópio cassegrain é mais difícil de ser obtido do que um telescópio newtoniano.

Durante cada uma das etapas de construção do telescópio, é possível incentivar a discussão de fenômenos ópticos que, em geral, são abordados apenas teoricamente em sala de aula, através de deduções e utilizações simples de equações, o que poucas vezes leva alunos do Ensino Médio e, em especial os de cursos de graduação a se sentirem motivados no aprendizado desses conteúdos. A tabela 2 apresenta as etapas envolvidas na construção do aparelho e quais os conteúdos que podem ser estudado em cada uma delas.

Cada uma das etapas da tabela 2 deve ser explorada de acordo com o nível de ensino com que se está trabalhando. Assim, para alunos de curso de graduação em Física, a ênfase é dada aos detalhes dos princípios físicos envolvidos, principalmente na análise da superfície do espelho, quando o critério de Rayleigh e fenômenos de interferência e difração são discutidos ${ }^{10}$. Também para esses alunos, na etapa do corte dos vidros, a formação de defeitos na superfície é abordada e como isso irá se refletir de forma indesejável no aparelho construído. 
Tabela 2 - Etapas da construção de telescópios e conteúdos relacionados.

\begin{tabular}{l|l}
\hline \multicolumn{1}{c|}{ Etapas da construção } & \multicolumn{1}{c}{ Conteúdos abordados } \\
\hline $\begin{array}{l}\text { Corte do vidro p/ espelho primá- } \\
\text { rio }\end{array}$ & Ocorrência de tensões e defeitos de superfície \\
$\begin{array}{l}\text { Esmerilhamento (espelho primá- } \\
\text { rio) }\end{array}$ & Formação de imagens em espelhos esféricos \\
Polimento & $\begin{array}{l}\text { Espelhos esféricos, parabólicos e hiperbólicos. } \\
\text { Discussão do método de Focault, aberrações } \\
\text { Análise da superfície }\end{array}$ \\
Espelhamento do vidro (primá- \\
rio)
\end{tabular}

Para alunos do Ensino Médio, juntamente com a utilização dos aparelhos é realizada uma descrição das etapas de construção, permitindo abordar, na prática, os princípios físicos envolvidos e suas aplicações, como a formação de imagens em lentes e espelhos ${ }^{9}$, instigando-os ao estudo de conteúdos mais complexos ${ }^{11}$ que poderão encontrar mais adiante em sua vida escolar. A formação de imagens utilizando dispositivos como lentes e espelhos é explicada esquematicamente na lousa e relacionada com os componentes do telescópio. Os alunos do Ensino Médio são convidados a manusear os telescópios, dando àqueles oportunidade de questionar sobre a construção, a vantagem em se utilizar três lupas na construção da lente ocular, a relação do tamanho do corpo (tubo de $p v c$ ) do aparelho com o diâmetro do espelho primário, etc. As etapas de construção apresentadas na tabela 2 são apresentadas, uma a uma, para alunos do Ensino Médio, relacionando-as com cada um dos possíveis conteúdos teóricos a serem abordados. $\mathrm{O}$ tempo necessário para a construção de um aparelho newtoniano é em torno de 140 horas que, no nosso caso, foram distribuídas ao longo de um ano. As necessidades de estrutura física para a construção dos aparelhos são bem pequenas, bastando apenas um espaço onde seja colocada uma pequena bancada de trabalho, uma pia com água corrente, mantendo o local limpo. A Fig. 5 ilustra algumas atividades de observação astronômicas desenvolvidas atendendo alunos do Ensino Médio, alunos de Graduação, alunos do Programa de Educação de Jovens e Adultos e comunidade em geral, utilizando o telescópio newtoniano e também lunetas. 


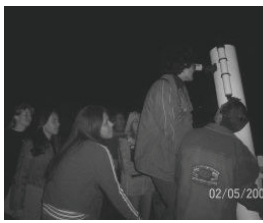

Observações astronômicas - alunos do curso de Pedagogia Unesp - Bauru.

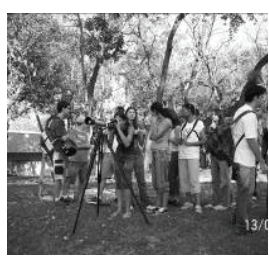

Utilização de lunetas com alunos do Ensino Médio e de graduação, abordando sua construção e funcionamento.

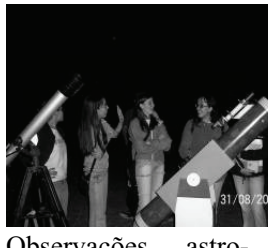

Observações astronômicas - alunos do Ensino Médio Bauru.

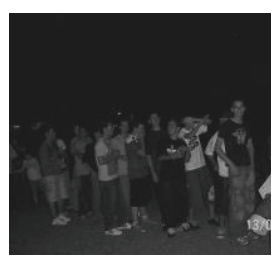

Observações astronômicas para a comunidade, geral.

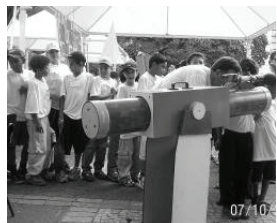

Demonstração do telescópio para alunos do Ensino Fundamental.

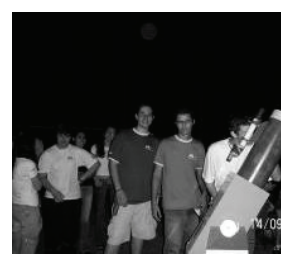

Observações Astronômicas com alunos do Ensino Médio do CTI - Unesp - Bauru.

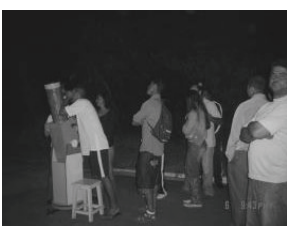

Observações com alunos do Programa de Educação de Jovens e Adultos.

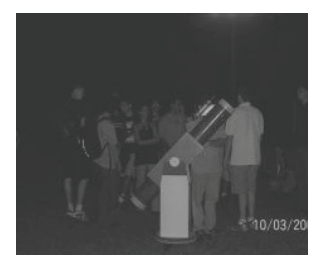

Observações para alunos ingressantes no curso de Licenciatura em Física - 2006.

Fig. 5 - Utilização do telescópio construído e de lunetas.

Durante a realização das atividades ilustradas, os alunos de graduação envolvidos no processo de construção podem explorar mais os aparelhos utilizados, descrevendo suas características e relacionando-as com o que está sendo observado. Assim, é discutida a Luminosidade, ou seja, quantas vezes mais o aparelho consegue captar luz comparado ao olho humano; a Magnitude Limite, que é a magnitude da estrela menos luminosa que o aparelho consegue captar; o Aumento ou Poder de Ampliação do aparelho e o Poder Separador, que é a capacidade do aparelho em separar pontos luminosos ${ }^{1}$. Entre outras coisas que podem ser abordadas, o fato de ser percebido em torno do planeta Júpiter um anel colorido pode ser explicado, fazendo-se referência ao estudo de aberrações cromáticas e como estas poderiam ser minimizadas com a utilização de outras lentes que podem ser associadas, como foi utilizado na obtenção da lente ocular. Assim, a formação de imagens, as diferenças entre espelhos planos (como é o espelho secundário do telescópio newtoniano) e côncavos (como é o espelho primário) e a associação de lentes oculares, são exploradas de maneira prazerosa e estimulante, quando os alunos de Ensino Médio são capazes de questionar os alunos da Licenciatura na 
explicação dos dispositivos envolvidos. Toda a discussão feita em torno das características do aparelho leva em conta sempre seu processo de construção, principalmente no que diz respeito à obtenção do espelho primário, que tem a maior parcela na qualidade do telescópio obtido.

Por outro lado, a partir da construção dos telescópios, teve origem a formação de um Grupo de Estudos de Astronomia (GEA), cuja principal proposta é oferecer outras ferramentas didáticas no ensino de Astronomia, utilizadas junto com os telescópios. Um dos principais resultados alcançados é a criação de animações sobre temas que despertam o interesse do público envolvido nas observações. Na Fig. 6, as páginas introdutórias de alguns dos trabalhos desenvolvidos pelo GEA estão ilustradas.

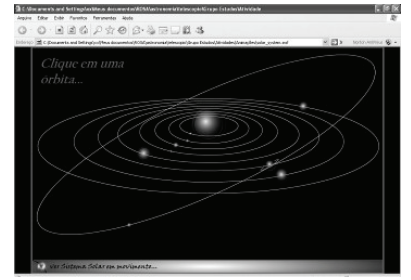

Animação sobre a órbita dos planetas e suas características.

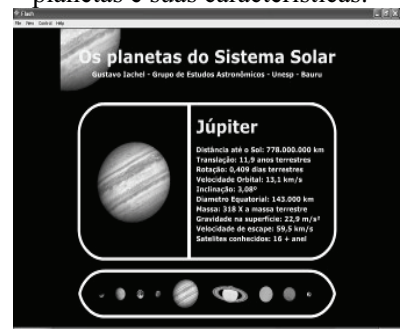

Catálogo (animado) sobre os planetas.

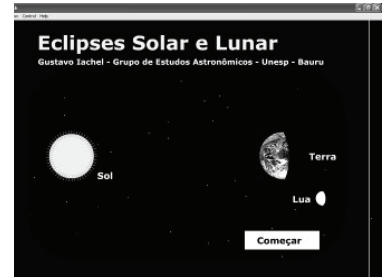

Animação sobre eclipse solar e lunar.

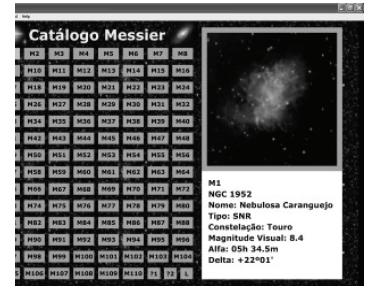

Catálogo (animado) sobre nebulosas e aglomerados.

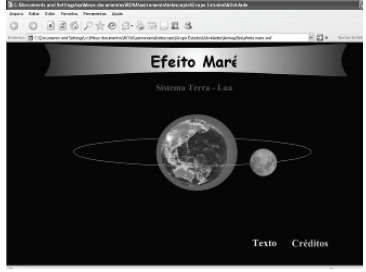

Animação sobre formação de Marés.

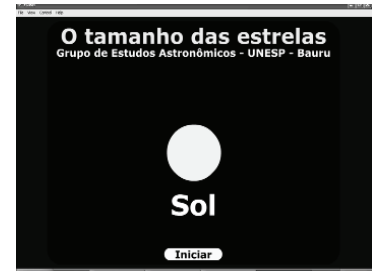

Animação sobre o tamanho das estrelas.

\section{Fig. 6 - Ferramentas didáticas criados pelo Grupo de Estudos de Astronomia.}

Com a utilização das ferramentas mostradas na figura acima tem se tornado possível abordar o entendimento de temas como a ocorrência de eclipses e marés, sem utilizar material acessível somente através da Internet e em livros didáticos que, muitas vezes, apresentam erros graves nas ilustrações ${ }^{3}$. Além das animações, programas obtidos comercialmente que descrevem o céu local são utilizados 
junto às observações, através de um microcomputador portátil (notebook). Além disso, quando a ferramenta utilizada permite que o aluno atendido possa interagir com ela, manuseando o computador, o aprendizado torna-se mais eficiente, como observado principalmente com alunos do Ensino Fundamental.

Outras atividades têm sido desenvolvidas abordando o ensino de Física e Astronomia, como mini-cursos, oficinas de construção de telescópios e construção de lunetas, palestras abordando temas da Astronomia, etc. Os resultados obtidos sempre são plenamente satisfatórios, pois uma grande parcela dos alunos de Ensino Fundamental, Ensino Médio e de Graduação envolvidos, dão continuidade ao estudo de Astronomia através de outras propostas. Na Fig. 7, são apresentadas algumas dessas atividades.

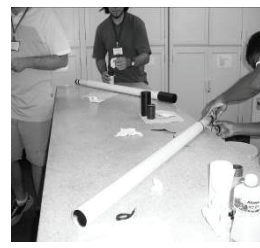

Oficina de lunetas para alunos do $4^{\circ}$ ano de Física.

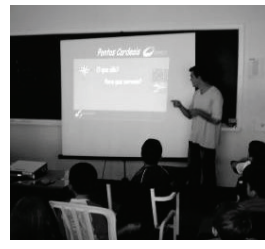

Palestra para alunos do Ensino Fundamental.
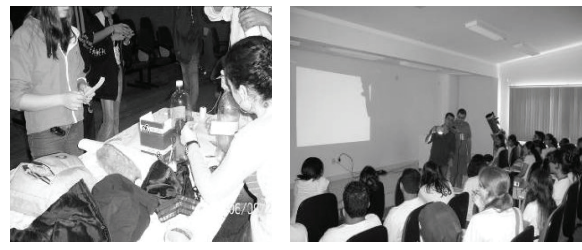

Curso para alunos

do Ensino Médio

(construção do

relógio de sol).

Palestra para alunos

do Ensino Médio.

Fig. 7 - Atividades desenvolvidas pelo Grupo de Estudos de Astronomia.

\section{Conclusões}

Com o desenvolvimento deste trabalho, tem sido possível a realização de palestras, mini-cursos e seminários dirigidos a alunos de Ensino Fundamental e Médio do município de Bauru. Além disso, também tem-se buscado atender a professores da Rede Pública de Ensino das Diretorias de Ensino de Bauru e região.

Assim, a seqüência utilizada para abordar o ensino de Física, iniciando com a construção dos telescópios (pelos alunos de Licenciatura em Física), passando para observações utilizando o aparelho construído (direcionada a alunos do Ensino Fundamental e Médio), utilização de recursos multimídias e cursos básicos de Astronomia parece ser uma fórmula bastante eficiente no ensino desse tema.

Além disso, os resultados iniciais do projeto de construção de telescópios aplicado ao ensino de Física mostram-se bastante promissores, pois o interesse de 
outros estudantes em participar do Grupo de Estudo de Astronomia é crescente. Assim, a construção do telescópio, a confecção de material didático para construção de telescópios e o atendimento ao público dado pelo Grupo de Estudos em Astronomia da Unesp-Bauru são etapas, em pleno desenvolvimento, que vieram intensificar o ensino de Astronomia no município de Bauru.

Outras atividades utilizando o aparelho construído também são executadas, envolvendo os alunos do curso de Licenciatura em Física em observações astronômicas, gerando discussões acerca de fenômenos físicos e de como transpor didaticamente os conceitos envolvidos na construção do aparelho.

Como conclusão geral deste trabalho, pode-se afirmar que a construção de telescópios, principalmente newtonianos, pelos alunos de Licenciatura em Física, tem sido fundamental para a motivação do ensino de Astronomia pelos futuros professores de Física. Além disso, as sessões de observação do céu, utilizando os aparelhos construídos, têm gerado inúmeras discussões sobre os conceitos físicos inerentes à construção, como formação de imagens, utilização de conjuntos de lentes, diferenças entre espelhos planos e esféricos, fatores de dificuldades no processo de construção, possibilidades de observação utilizando um aparelho ou outro, etc. Com isto, é possível contribuir efetivamente para a formação dos futuros professores de Física, e outras licenciaturas, dando a eles fundamentação teórica e prática na abordagem do ensino de Astronomia, e incentivar os estudantes de Ensino Fundamental e Médio a questionar e entender fenômenos físicos, principalmente aqueles relacionados à óptica geométrica, através do conhecimento e utilização dos aparelhos.

\section{Agradecimentos}

Os autores agradecem à Fundação para o Desenvolvimento da Unesp (FUNDUNESP), Fundação de Amparo a Pesquisa do Estado de São Paulo (FAPESP), Pro Reitoria de Extensão Universitária da Unesp (PROEX) e ao Conselho Nacional de Desenvolvimento Científico e Tecnológico (CNPq) pela concessão de recursos financeiros e bolsas de Iniciação Científica. Agradecem ao Instituto de Pesquisas Meteorológicas da Unesp (IPMET) pela concessão do espaço para observações e ao Sr. Lionel José Andriatto pela colaboração no projeto de construção dos aparelhos. 


\section{Bibliografia}

${ }^{1}$ MOURÃO, R. R. F. Manual do Astrônomo. Rio de Janeiro: Jorge Zahar Editor, 2001.197 p.

${ }^{2}$ CANIATO, R. O que é Astronomia. São Paulo: Brasiliense, 1994. 100 p.

${ }^{3}$ LANGHI, R. Um estudo exploratório para a inserção da Astronomia na formação de professores dos anos iniciais do Ensino Fundamental. 2004. 240 f. Dissertação (Mestrado em Educação) - Faculdade de Ciências, Universidade Estadual Paulista, Bauru, São Paulo.

${ }^{4}$ CARVALHO, A. M. P.; GIL-PÉREZ, D. Formação de professores de ciências. São Paulo: Cortez, 2006. 120 p.

${ }^{5}$ BOCZKO, R. Conceitos de Astronomia. São Paulo: Edgard Blucher, 1984. 429 p.

${ }^{6}$ BERNARDES, T. O. et al. Abordando o ensino de óptica através da construção de telescópios. Revista Brasileira de Ensino de Física, São Paulo, v. 28, n. 3, p. 391-396, dez. 2006.

${ }^{7}$ SCHERMAN, J.; VIOLA, A. H. Construccion de telescópios - Manual del Aficionado. Buenos Aires: Asociación Argentina de Astronomia, 1960. 100 p.

${ }^{8}$ NICOLINI, J. Manual do Astrônomo Amador. Campinas, SP: Papirus Livraria e Editora, 2004. 384 p.

${ }^{9}$ YOUNG, H. D.; SEARS; ZEMANSKY. Física IV: Ótica e Física moderna, São Paulo: Addison Wesley, 2004, 426 p.

${ }^{10}$ YOUNG, M. Ótica e lasers. São Paulo: Editora da Universidade de São Paulo, $1998,435 \mathrm{p}$.

${ }^{11}$ ABDALLA, M. C. B.; NETO, T. V. Novas janelas para o Universo. São Paulo: Editora Unesp, 2005.118 p. 